\title{
OPTIMALISASI PERAWATAN ALAT-ALAT KESELAMATAN SEBAGAI PENUNJANG KESELAMATAN AWAK KAPAL DI KN. BIMA SAKTI
}

\author{
Firdaus Sitepu \\ Dosen Program Studi Nautika PIP Semarang
}

\begin{abstract}
As for target of writing of this handing out is to know optimalization treatment of safety appliance as supporter safety of crew man in KN. Bima Sakti. Pursuant to the target, hence this handing out take title "Optimalization Treatment of Appliance Safety As Supporter Safety of Crew Man In Kn. Bima Sakti".

Method weared by writer in writing this handing out is descriptive method. As for research obyek is KN. Bima Sakti. Method data collecting use field study, Bibliography study (research library) and documentation.

Pursuant to result of research which have been conducted, hence can be taken by some conclusion that is things causing safety appliance do not function in an optimal fashion moment used in training in KN Bima Sakti is because lack of the understanding of hitting procedure treatment of real correct safety appliance pursuant to regulation of treatment of safety appliance according to Solas (Safety Of Life Sea at) and because lack of facility equipments of treatment to safety appliance given by company so that activity of treatment become less maximal. Things related to execution to be is optimal of treatment of safety appliance better in KN Bima Sakti is with treatment of lifeboat, benefactor raft ( liferaft), benefactor float ( lifebuoy), benefactor clothes ( jacket life) executed by inspection periodical to safety appliance like weekly periodic inspection, monthly and annual according to procedure regulation of Solas (Safety Of Life Sea at), and also inspection of equipments of safety appliance is also checked by the parts of the safety appliance accurately and detail as according to tables of checklist inspection of safety appliance. method Treatment of safety appliance, because method treatment of safety appliance as base from make-up of efficiency in is optimal of activity from safety appliance on board so that the safety appliance can be used in an optimal fashion by all crew man if happened emergency on board.
\end{abstract}

Keywords: optimalization treatment of safety appliance, safety supporter, supporting crew safety.

\section{PENDAHULUAN}

Dalam abad modern sekarang ini transportasi laut masih memegang peranan yang sangat dominan sebagai alat angkut yang belum dapat digantikan dengan jenis angkutan lain, karena angkutan laut merupakan suatu sistem pengangkutan dalam jumlah besar yang belum dapat dilakukan oleh jenis angkutan lainnya. Setiap perusahaan selalu menuntut agar pegawainya yang ada di atas kapal bekerja dengan sebaikbaiknya, dan bukan hanya mencari nafkah untuk diri sendiri tapi juga untuk keluarganya. Sehingga mereka mampu bekerja secara optimal dan memperhatikan keselamatan kerja mereka.
Badan Pengembangan Sumber Dana Manusia Perhubungan baru memiliki dua kapal latih untuk taruna. Salah satunya KN. Bima Sakti yang kini dioperasikan di PIP Semarang, Jawa Tengah. "Ke depan, kapal latih untuk taruna akan ditambah dengan dana dari APBN, termasuk APBN P 2015. Kapal tersebut juga bisa difungsikan sebagai kapal untuk melayani rute perintis," terang Tommy.

Badan Pengembangan Sumber Daya Manusia (BPSDM) Perhubungan akan belanja kapal dan pesawat latih untuk taruna pada tahun 2015. Untuk kapal latih akan membeli enam unit dan diproyeksikan juga akan dioperasikan di rute-rute pelayaran 
perintis di Indonesia "pernyataan Kepala BPSDM Perhubungan Wahyu Satrio Utomo kepada beritatrans.com di Jakarta. Menurutnya, enam kapal latih tersebut akan didistribusikan ke BP2IP Banda Aceh, PIP Semarang, Poltekpel Surabaya, PIP Makasar, BP2IP Sulawesi Utara dan BP2IP Sorong. Kapal tersebut dibangun di galangan kapal dalam negeri. Saat ini semua proyek pengadaan barang dan jasa dengan dana APBN lebih diprioritaskan untuk perusahaan dalam negeri" jelas Tommy.

Walaupun

$$
\text { kapal-kapal }
$$

yang

dioperasikan sudah berusia tua namun tetap dituntut harus dalam keadaan laik laut agar tidak membahayakan kapalnya sendiri, anak buah kapal, muatan yang dibawanya dan juga lingkungannya. Menurut Suyono (2000:48) pengertian dari laik laut (Seaworthness) adalah:

1. Kapal layak untuk menghadapi berbagai resiko dan kejadian secara wajar dalam pelayaran.

2. Kapal layak untuk menerima muatan dan mengangkutnya serta melindungi keselamatan muatan dan Awak kapal nya.

3. Kapal tidak mencemari lingkungan

Divisi operasi dan divisi armada merupakan bagian yang memegang peranan penting dalam melakukan tindakan perawatan dan perbaikan terhadap kapal-kapal suatu perusahaan pelayaran yang diharapkan dapat meningkatkan kemampuan operasi perusahaan tersebut.

Keselamatan kerja merupakan salah satu faktor mutlak yang harus dipenuhi agar anak buah kapal dapat bekerja dengan aman dan maksimal. Dengan adanya alat-alat keselamatan sebagai penunjang keselamatan para awak kapal diharapkan dapat memperkecil atau dapat dihilangkan sama sekali resiko kecelakaan kerja di kapal. Sikap yang hati-hati dan tidak ceroboh dalam bertindak akan membuat pihak lain tidak mengalami kekhawatiran. Banyak anak buah kapal yang bekerja hanya sekedar memenuhi kewajiban sesuai tanggungjawabnya tanpa memiliki kepedulian diri sendiri, orang lain dan lingkungan. Tidak jarang suatu pekerjaan baik di darat maupun di kapal serta apapun bentuknya, karena kurang memperhatikan keselamatan sehingga menimbulkan korban.

Sebagai contoh kasus yang pernah terjadi di atas kapal, salah satu juru mudi matanya terkena serpihan karat pada saat mengetok karat karena tidak memakai kacamata pelindung sehingga harus mendapat pertolongan pertama dan harus diobati. Dengan adanya kejadian tersebut maka kemajuan yang dicapai menjadi kurang berarti dan malah membahayakan kehidupan pekerjanya. Kecelakaan yang terjadi di kapal selain menjadi hambatan-hambatan langsung juga merupakan kerugian-kerugian tidak langsung, yakni kerusakan mesin dan peralatan kerja, terhentinya pekerjaan dan proses produksi untuk beberapa saat, kerusakan pada lingkungan kerja dan sebagainya.

Beberapa kecelakaan yang terjadi di kapal memperlihatkan bahwa untuk setiap kecelakaan ada faktor penyebabnya. Sebabsebab tersebut bersumber pada alat-alat mekanik dan lingkungan serta kepada manusianya sendiri. Untuk mencegah terjadinya kecelakaan, penyebab-penyebab ini harus diperkecil atau dihilangkan sama sekali, antara lain dengan melakukan perawatan terhadap alat-alat keselamatan. Kapal memiliki berbagai macam peralatan yang menunjang kelancaran operasi kapal, dimana alat-alat tersebut memiliki fungsi masing-masing. Sedangkan alat-alat tersebut memerlukan suatu perawatan yang rutin, agar dapat menunjang kelancaran operasi kapal dan memenuhi ketentuan pemerintah tentang kelaiklautan kapal.

Pengaruh pemerintah serta organisasiorganisasi seperti International Maritime Organization (IMO), International Labour Organization (ILO) ikut memberikan tekanan terhadap perusahaan-perusahaan pelayaran untuk lebih memperhatikan segi keselamatan dari pada awak kapalnya.

Peraturan-peraturan yang terkait dengan keselamatan kerja di kapal antara lain:

1. Standart Training Certificate and Watchkeeping (STCW) Amandemen 2010, mengenai standar pelatihan bagi para pelaut. 
Firdaus Sitepu, Dosen Program Studi Nautika PIP Semarang

2. Badan Diklat Perhubungan Tahun 2000, mengenai petunjuk-petunjuk tentang alatalat keselamatan beserta kegunaannya.

Peraturan-peraturan tersebut secara global bertujuan untuk mencegah atau mengurangi kecelakaan dan akibatnya, serta menjamin keselamatan kerja bagi anak buah kapal di atas kapal. Di dalam Peraturan Pemerintah No. 51 tahun 2002 tentang Perkapalan disebutkan bahwa, keselamatan kapal adalah material, konstruksi, bangunan, permesinan, kelistrikan, stabilitas dan tata susunan serta termasuk perlengkapan radio dan elektronika kapal. Beberapa kejadian kerusakan pada perawatan di kapal terancam oleh adanya beberapa kerusakan yang tidak dengan segera diatasi atau diperbaiki.

Perawatan merupakan hal yang paling penting dalam mempertahankan kehandalan fasilitas-fasilitas yang diperlukan masyarakat modern, tetapi hanya sedikit bidang-bidang yang mampu berperan begitu dominan seperti dalam dunia pelayaran. Mempertahankan atau menjaga kondisi kapal, adalah tujuan utama setiap tindakan perawatan. Pemilik menghadapi berbagai masalah untuk menentukan standar perawatan kapalnya yaitu bagaimana agar standarnya terpenuhi sesuai dengan aturan yang telah ditetapkan dalam International Safety Management Code (ISM Code), misalnya aturan yang mengharuskan kapal untuk naik dock dalam jangka waktu 5 tahun sekali.

Pada kenyataannya perusahaan pelayaran tersebut hanya memikirkan supaya kapalnya dapat memberikan keuntungan yang sebesar-besarnya atau hanya terfokus pada uang saja, kadang-kadang perusahaan pelayaran tersebut tidak memperhatikan atau bahkan mengabaikan faktor-faktor lain. Hal yang dapat menunjang keselamatan pengoperasian kapal tersebut agar dapat laik laut seperti masalah pengawakan yang baik, perawatan (maintenance) ataupun galangan kapal (docking). Perawatan kapal juga berhubungan erat dengan keselamatan pelayaran sehingga Port State Control (PSC) juga ditugasi memeriksa pelaksanaan konvensi-konvensi internasional, antara lain Safety Of Life At Sea (SOLAS), Standart Training Certificate and Watchkeeping (STCW).

Dengan alasan tersebut peneliti mengangkat dan membahas tentang optimalisasi perawatan alat-alat keselamatan sebagai penunjang keselamatan awak kapal di KN. Bima Sakti. KN. Bima Sakti merupakan Kapal latih kebanggaan PIP Semarang, keberadaannya menjadikan nilai tambah tersendiri untuk Politeknik Ilmu Pelayaran Semarang. KN. Bima Sakti merupakan kapal hibah dari Navigasi Laut untuk Badan Diklat PIP Semarang. Dengan adanya kapal latih ini diharapkan proses pembelajaran akan lebih sempurna dan aplikatif guna menunjang terwujudnya visi dan misi PIP Semarang menghasilkan tenaga kepelautan profesional bertarap internasional.

\section{FAKTA DAN PERMASALAHAN}

\section{A. Fakta}

KN. Bima Sakti merupakan Kapal latih kebanggaan PIP Semarang, keberadaanya menjadikan nilai tambah tersendiri. Politeknik Ilmu Pelayaran (PIP) Semarang. KN. Bima Sakti merupakan kapal hibah dari Navigasi laut untuk Badan Diklat PIP Semarang. Dengan adanya kapal latih ini diharapkan proses pembelajaran akan lebih sempurna dan aplikatif guna menunjang terwujudnya Visi dan Misi PIP Semarang menghasilkan tenaga kepelautan profesional bertarap Internasional. 


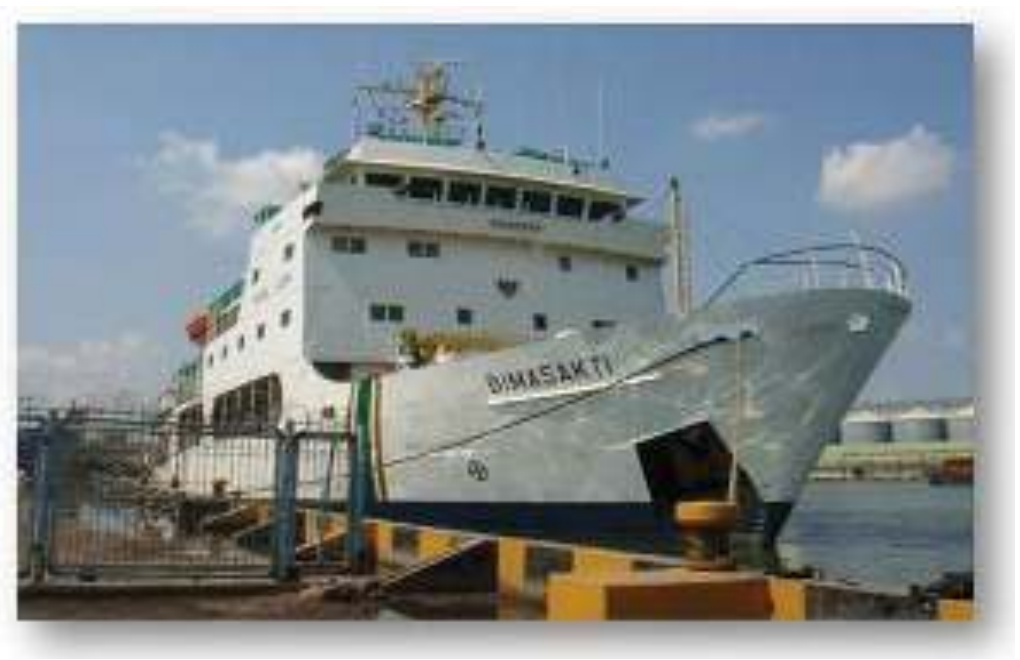

Gambar Kapal KN. Bima Sakti

\section{Ships's Particiular}

Nomor/Nama Kapal

Tahun Pembuatan

Galangan pembangunan Kapal

\section{Ukuran Utama}

Panjang Seluruhnya (L.O.A)

Lebar (M.Moulded)

Tinggi (Depth)

Sarat Air (Depth)

BRT/GRT/DWT

Kecepatan Saat Awal

Kecepatan Saat ini

Kapasitas Tanki Air Tawar

Kapasitas Tanki BBM

Kapasitas Tanki Minyak Lumas

Akomodasi Awak Kapal

Akomodasi Penumpang

Material Lambung

Kemapuan Jelajah
: KN. Bima Sakti

: 1984

: Makum Belanda

: 59,75 Meter

: 3,0 Meter

: 6,10 Meter

: 3,8 Meter

: 1373,15 Ton

: 12 Knot

: $11 \mathrm{Knot}$

: 200.000 Liter

: 220.000 Liter

: 4000 Liter

: 65 Orang

:-- orang

: Baja

: 4488 Mil

\section{Mesin Induk}

Jumlah

Merk Type

Daya Kapasitas

Konsumsi Bahan Bakar / jam

Kondisi Teknis

: 2 Unit

: Bolnes / 10 DNL

: $303 \mathrm{HP}$

: 30 Liter

:\%

\section{Mesin Bantu}

Jumlah

Merk/Type

Daya/Kapasitas

: Mercedes Benz/ OM 424

: 303 HP

: 30 Liter

Kondisi Teknis

$: \%$ 
Firdaus Sitepu, Dosen Program Studi Nautika PIP Semarang

\section{B. Fakta kondisi}

Pada bagian ini, penulis akan membahas mengenai hasil-hasil penelitian yang diperoleh berdasarkan kegiatan penelitian yang telah dilaksanakan di $\mathrm{KN}$. Bima Sakti. Selama proses kegiatan penelitian peneliti menemukan beberapa fakta yang kemudian akan peneliti bahas. Beberapa permasalahan tersebut yaitu :

1. Alat-alat keselamatan tidak bekerja secara optimal saat digunakan dalam pelatihan di atas kapal

2. Pelaksanaan untuk mengoptimalkan perawatan alat-alat keselamatan dengan baik

3. Inspeksi mingguan

4. Inspeksi bulanan

\section{Permasalahan}

Pada bagian ini, penulis akan menganalisa mengenai hasil-hasil yang diperoleh berdasarkan kegiatan analisa yang telah dilaksanakan di KN. Bima Sakti. Selama proses kegiatan penelitian peneliti menemukan beberapa permasalahan yang kemudian akan peneliti analisa. Beberapa permasalahan tersebut yaitu:

1. Mengapa alat-alat keselamatan tidak berfungsi secara optimal saat digunakan dalam pelatihan di atas kapal?

2. Bagaimana cara untuk mengoptimalkan perawatan alat-alat keselamatan dengan baik?

\section{METODE PENELITIAN}

Metode penelitian dilakukan berdasarkan metode deskriptif, yaitu dengan memaparkan langsung yang dianalisa di atas kapal. Kemudian diadakan tindakan-tindakan perawatan dan perbaikan.

\section{HASIL DAN DISKUSI}

\section{A. Analisis Penyebab Masalah}

Melalui sistem yang terencana pula dilakukan pengawasan terhadap mesin-mesin baik mesin utama maupun mesin bantu. Sudah tentu masalah besarnya biaya yang dikeluarkan dalam perbaikan dan perawatan kapal akan berpengaruh terhadap laba operasional kapal itu sendiri, karena Anak Buah Kapal tidak akan bisa bekerja tanpa didukung dengan peralatan-peralatan yang diperlukan.

Karena kapal-kapal yang beroperasi pada sudah berumur, maka sangat banyak perawatan-perawatan yang dilakukan dengan melakukan perawatan-perawatan yang berkesinambungan, baik perawatan preventif maupun korektif. Diharapkan supaya perawatan dan perbaikan itu dapat meminimalisir kerusakan sehingga kapalkapal tersebut dapat mencapai target yang diharapkan, yaitu pendapatan hasil usaha operasional kapal dan keselamatan kapal.

Kapal dapat laik membutuhkan perawatan dan perbaikan terutama mesinmesin, lambung kapal, bagian ruang muat, tanki ballast, alat-alat bongkar muat, alat-alat keselamatan dan alat-alat navigasi, agar kapal selalu berada di lautan dan dapat mengangkut serta memindahkan orang dan barang dari satu pelabuhan ke pelabuhan yang lain dan mesin-mesin selalu berjalan lancar dan tahan lama meskipun dalam kondisi cuaca yang buruk. Dalam mendukung proses pengoperasian kapal diperlukan suatu penanganan yang baik dalam perawatan, agar kapal tersebut dapat lancar dalam pengoperasiannya sesuai dengan yang diinginkan. Dengan kata lain perawatan adalah salah satu hal yang penting untuk menunjang beroperasinya kapal dan keselamatan awak kapal.

\section{B. Analisis Pemecahan Masalah}

Keselamatan pelayaran adalah segala hal yang ada dan dapat dikembangkan dalam kaitannya dengan tindakan pencegahan kecelakaan pada saat pelaksanaan kerja di bidang pelayaran. International Safety Management Code (ISM Code) sebagai peraturan manajemen keselamatan internasional untuk keamanan maupun keselamatan pengoperasian kapal dan pencegahan pencemaran lingkungan laut yang ditetapkan oleh Dewan Keselamatan Maritim IMO yang masih dimungkinkan untuk diamandemen. 
Persepsi Crew dan Manajemen Dalam Penerapan ISM Code Bagi Keselamatan Pelayaran dan Perlindungan Lingkungan Laut ISM Code merupakan produk dari IMO (International Maritime Organization) yang akhirnya diadopsi oleh SOLAS pada tahun 1994 (Safety of Life at Sea). ISM Code merupakan standard Sistem Manajemen Keselamatan untuk pengoperasian kapal secara aman dan untuk pencegahan pencemaran di laut. Intinya ISM Code ini bertujuan untuk menjamin keselamatan di laut, mencegah kecelakaan atau kematian, dan juga mencegah kerusakan pada lingkungan dan kapal.

Sistem pada IMS Code harus disetujui oleh Flag Administration (Pemerintah suatu negara yang benderanya digunakan oleh kapal yang bersangkutan) atau suatu badan yang ditunjuk oleh Flag Administration, kemudian sertifikat dikeluarkan. Sebelum perusahaan dan kapalnya dioperasikan keduanya harus disertifikasikan terhadap ISM Code. Sertifikat ISM Code dapat diartikan sebagai suatu lisensi untuk menjadi Ship Operator.

Optimalisasi perawatan alat-alat keselamatan sebagai penunjang keselamatan awak kapal di KN. Bima Sakti

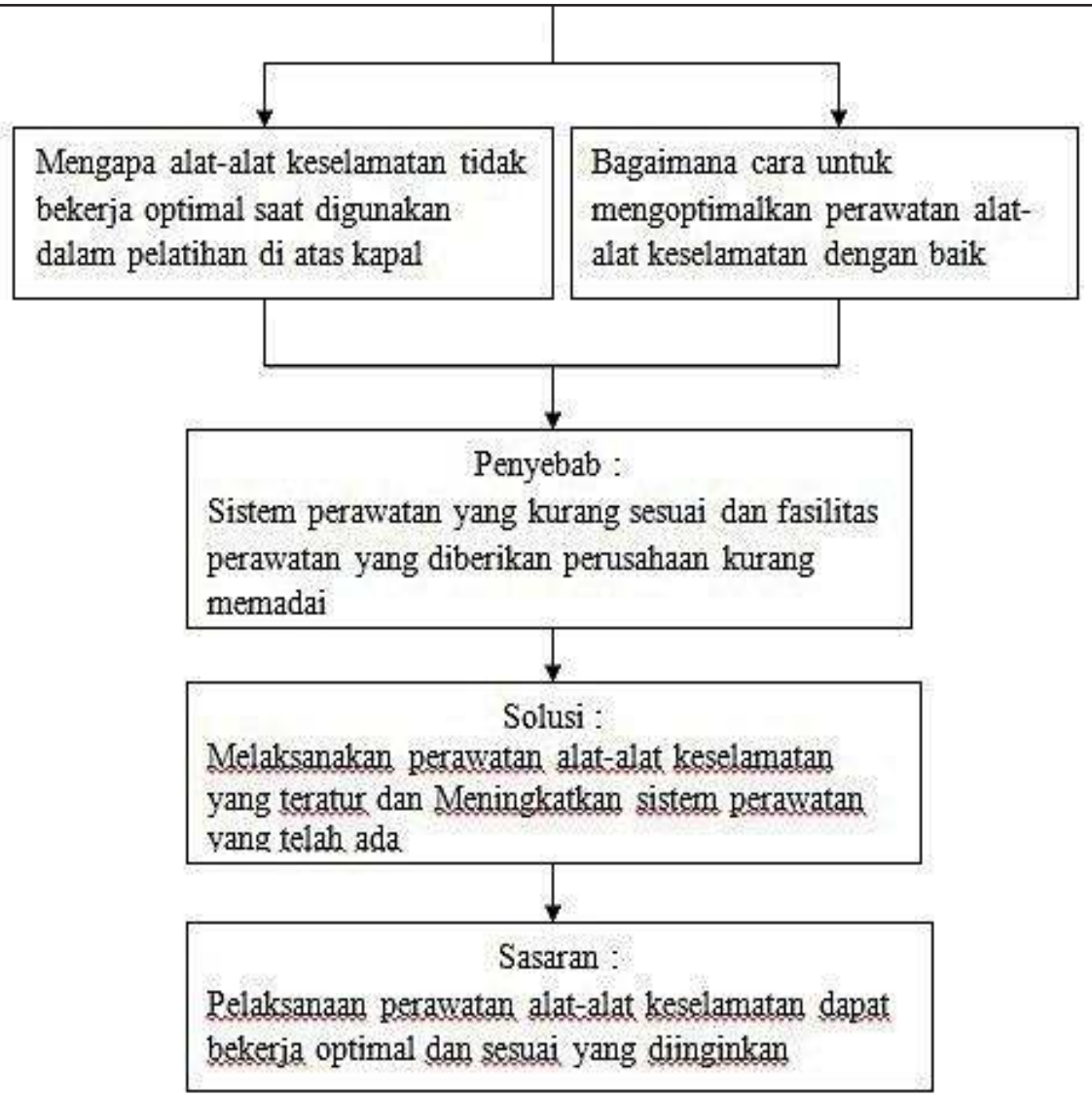

Gambar Kerangka Berpikir

Berdasarkan bagan kerangka berpikir di atas dapat diketahui penyebab dan penanganan perawatan alat-alat keselamatan di KN. Bima Sakti, adapun penjabaran dari kerangka berfikir di atas ialah sebagai berikut:

1. KN. Bima Sakti merupakan kapal latih kebanggaan PIP Semarang, keberadaannya menjadikan nilai tambah tersendiri untuk
Politeknik Ilmu Pelayaran Semarang. KN. Bima Sakti merupakan kapal hibah dari Navigasi laut untuk Badan Diklat PIP Semarang. Dengan adanya kapal latih ini diharapkan proses pembelajaran akan lebih sempurna dan aplikatif guna menunjang terwujudnya visi dan misi PIP Semarang 
Firdaus Sitepu, Dosen Program Studi Nautika PIP Semarang

menghasilkan tenaga kepelautan profesional bertarap internasional.

2. Adapun faktor-faktor penyebab kurangnya perawatan alat-alat keselamatan di KN.

Bima Sakti adalah sebagai berikut:

a. Fasilitas perawatan yang diberikan perusahaan kurang memadai

b. Kurangnya perawatan pada alat-alat keselamatan

c. Kurangnya kesadaran awak kapal akan pentingnya alat-alat keselamatan

3. Dari permasalahan alat-alat keselamatan di KN. Bima Sakti satu tidak bekerja secara optimal maka diambil tindakan penanganan, meliputi:

a. Melaksanakan perawatan alat-alat keselamatan yang teratur dan menambah fasilitas perawatan

b. Meningkatkan sistem perawatan yang telah ada atau mengubah sistem perawatan yang lebih sesuai

4. Sasaran dari seluruh tindakan yang telah dilakukan yaitu pelaksanaan perawatan alat-alat keselamatan dapat bekerja optimal dan sesuai yang diinginkan.

\section{KESIMPULAN}

Berdasarkan hasil penelitian dan pembahasan yang telah dilakukan, maka dapat diambil beberapa kesimpulan yaitu:

1. Hal-hal yang menyebabkan alat-alat keselamatan tidak berfungsi secara optimal saat digunakan dalam pelatihan di KN. Bima Sakti adalah:

a. Karena kurangnya pemahaman mengenai prosedur perawatan alat-alat keselamatan yang benar sesuai dengan ketentuan peraturan perawatan alat-alat keselamatan sesuai SOLAS (Safety of Life at Sea).

b. Karena kurangnya fasilitas peralatan perawatan terhadap alat-alat keselamatan yang diberikan oleh perusahaan sehingga kegiatan perawatan menjadi kurang maksimal.

2. Hal-hal yang berkaitan dengan pelaksanaan untuk mengoptimalkan perawatan alat-alat keselamatan dengan baik di KN. Bima Sakti adalah: a. Dengan perawatan sekoci penolong (lifeboat), rakit penolong (liferaft), pelampung penolong (lifebuoy), baju penolong (life jacket) dilaksanakan pemeriksaan secara periodik terhadap alat-alat keselamatan seperti pemeriksaan berkala mingguan, bulanan dan tahunan sesuai prosedur peraturan SOLAS (Safety Of Life at Sea), serta pemeriksaan peralatan alat-alat keselamatan juga diperiksa bagianbagian alat-alat keselamatan tersebut secara teliti dan detail sesuai dengan tabel checklist pemeriksaan alat-alat keselamatan.

b. Metode perawatan alat-alat keselamatan, karena metode perawatan alat-alat keselamatan sebagai dasar dari peningkatan efisiensi dalam mengoptimalkan kerja dari alat-alat keselamatan di atas kapal sehingga alatalat keselamatan tersebut dapat digunakan secara optimal oleh seluruh awak kapal jika terjadi keadaan darurat di atas kapal.

\section{DAFTAR PUSTAKA}

Badan Diklat Perhubungan. 2005. Model International Safety Management Code (Kode Manajemen Keselamatan Internasional). Cetakan Pertama. Jakarta

Badan Koordinasi Keamanan Laut Indonesia. 2009.Kebijakan Keselamatan dan Keamanan Transportasi Laut. Jakarta: BAKORKAMLA

Herbert-Burns, R., Bateman S., Lehr P. 2009. Lloyd MIU Handbook Of Maritime Security. CRC Press

IMO. 2010. International Convention on Standart of Training Certification and Watchkeeping for Seafarers (STCW). Amandement 2010. London: International Maritime Organization 
Jinca, M. Yamin. 2011. Transportasi Laut Indonesia-Analisis Sistem dan Studi Kasus. Surabaya: Brilian Internasional

Mandaku. H. 2010. Analisis Kebutuhan Transportasi Penyeberangan Pada Lintasan Hunimua-Waipirit, Jurnal Arika Vol 4, No. 1. Ambon: UNPATTI

Moleong, Lexy J. 2006. Metode Penelitian Kualitatif. Bandung: PT Remaja Rosdakarya

Narbuko, Cholid dan Abu Achmadi. 2009. Metode Penelitian. Jakarta: Bumi Aksara

Nasution. 2007. Metode Research. Jakarta: PT Bumi Aksara

Nasution, M. N. 2004. Manajemen Transportasi. Jakarta: Ghalia Indonesia

Nazir, Moh. 2005. Metode Penelitian. Bogor: Ghalia Indonesia

Noor, Juliansyah. 2011. Metode Penelitian. Jakarta: Predana Media Group

Okezone. 2012. http://news.okezone.com, Diakses Tanggal 26 Juli 2012 jam 21.35 WIT

Raco. 2010. Metode Penelitian Kualitatif. Jakarta: Gramedia Widiasarana Indonesia
Rodrigue J. P., Comtois C., and Slack B. 2006. The Geography of Transport Systems. London \& New York: Routledge

Salim, Abbas. 2006. Manajemen Transportasi. Jakarta: Raja Grafindo Persada

Soewedo, Hananto. 2009. Lingkungan dan Keselamatan Transportasi. Jurnal Manajemen Mutu, Vol. 8, No. 2. Jakarta: UPN

Stopford, Martin. 2000. Maritime Economics. London: Routledge

Suara Merdeka. 2012. http://www.suaramerdeka.com, Diakses Tanggal 26 Juli 2012 jam 21.32 WIT

Sugiyono. 2009. Metode Penelitian Bisnis. Bandung: Alfabeta - 2009. Metode Penelitian Kualitatif dan $R \& D$. Bandung: Alfabeta

Sulistijo. 2010. International Safety management Code. Semarang: PIP Semarang

Umar, Husein. 2008. Metode Penelitian Untuk Skripsi dan Tesis Bisnis. Edisi Kedua. Jakarta: Raja Grafindo Persada

Wijnolst, Niko dan Wergeland Tor. 1997. Shipping. Delft University Press 